\title{
RESTAURACIÓN DE LA ILUMINACIÓN NATURAL
}

\author{
(RESTORATION OF NATURAL ILLUMINATION)
}

\author{
Margarita de Luxán García de Diego, Dr. Arquitecto \\ Directora del Seminario de Arquitectura Integrada en su Medio Ambiente \\ y Profesora de la E.T.S. de Arquitectura de Madrid.
}

\section{RESUMEN}

Este comentario aborda el problema de la desvirtuación de los valores espaciales que se plantea en los edificios al alterar las condiciones de la iluminación natural originales.

Señala su incidencia creciente a partir de la instalación, en arquitecturas que habian sido construidas con anterioridad al uso de estos sistemas, de iluminaciones artificiales eléctricas que intentan sustituir a la luz solar sin respetar los efectos ambientales creados por élla.

Toma como ejemplo tres edificios arquetipicos en la Arquitectura española: el Museo del Prado de Madrid, el Monasterio de El Escorial y la Mezquita de Córdoba

\section{SUMMARY}

This article tackles the problem of the distorsion of spatial values in buildings brought about by altering original natural illumination.

This phenomenon is on the increase do to the installation of artificial electrical lighting in structures that were planned and built before these systems came into use. Said lighting systems attempt to substitute solar light but fail to respect the atmosphere created by natural light in these structures.

The article looks at three buildings which are representative of Spanish architecture: the Prado Museum in Madrid, the Monastery of El Escorial and Córdoba's "Mezquita" (Mosque).
La inmensa mayoría de las obras arquitectónicas reconocidas de nuestro patrimonio edificado, así como los objetos que contienen: pinturas, esculturas, etc., fueron proyectadas y ejecutadas en función de su percepción con una iluminación natural.

Esa iluminación, manejada por el arquitecto, es uno de los elementos más importantes y sutiles de la configuración de los espacios construidos; y las luces y las sombras articulan y significan la lectura total de las obras; sin embargo, cada vez con más frecuencia, resulta imposible disfrutar las arquitecturas con su iluminación original.

A la hora de restaurar los edificios, en la práctica habitual, se refuerzan los sistemas portantes, se reponen los materiales y rehacen los acabados, y se tiende a rescatar las decoraciones y ornatos, respetando al máximo los elementos originales; pero la introducción de sistemas de iluminación artificial, con resultados que no suelen ser coherentes con las imágenes que se percibían bajo la luz natural, pueden desintegrar la estructura visual, global y parcial, del espacio arquitectónico.
Se comprende que una iluminación artificial nocturna alarga el periodo de visita, uso y disfrute de los edificios; sin embargo, lo que parece contradictorio es que este tipo de iluminación sustituya durante todo el dia a la natural, desvirtuando y haciendo imposible la lectura del espacio pensada por los autores, y restando la posibilidad de apreciar la variación dinámica que con el recorrido del sol, a lo largo del dia, enriquece la imagen arquitectónica.

Agrava el problema el hecho de que, muchas veces, la nueva iluminación eléctrica está pensada con un carácter de escenografía excesivamente grandilocuente, $y$ atiende fundamentalmente a dos exigencias: el refuerzo puntual visual de algunos elementos aisladamente: los más decorados, los más curiosos, los que contienen algo raro y que no tienen por qué coincidir con los más importantes; con ello se deshace la estructura perceptiva global básica del espacio; y la voluntad de ocultar las instalaciones (redes, equipos y aparatos), con lo que las direcciones en las que la luz incide sobre la obra suelen estar muy forzadas, y las imágenes consiguientes resultan, cuanto menos, extrañas y, desde 
luego, diferentes a las que veríamos en el caso de respetar la luz natural.

El abuso al utilizar la iluminación artificial, va aumentando con la posibilidad de conseguir algún dinero tapando los huecos al exterior, dejando los recintos como bocas de lobo, e instalando unas cuantas máquinas tragaperras con lámparas temporizadas que, al encenderse, iluminan brillante y únicamente zonas $u$ objetos inverosímiles (un cuadro hecho de miga de pan mascado que le regalaron a la reina unos visitantes anónimos, la señal supuestamente grabada en el suelo enlosado por una férrea bota del caballero medieval defenestrado desde una balconada, etc.). Además, en las que tienen iluminaciones continuas, cuanto más desaforadas y exageradas son, mayor es el celo de los guardianes de las mismas en mantenerlas encendidas sin descanso, con feroz determinación.

Este comentario, que más que nada es una llamada de atención, se puede hacer extensivo a muchos de nuestros edificios monumentales, y a otros antiguos a los que van alcanzando la fama y el progreso, voy a referirlo específicamente a tres edificaciones arquetípicas: el Museo del Prado de Madrid, el Real Monasterio de San Lorenzo de El Escorial y la Mezquita de Córdoba.

\section{Museo del Prado}

El Museo del Prado no pudo terminarse de construir por su arquitecto creador, Juan de Villanueva. Las alteraciones en la estructura de iluminación se produjeron básicamente con el cambio de uso: de Academia de Ciencias Naturales a Pinacoteca.

Edificio con un largo eje Norte-Sur en planta, buscaba el remarcarlo lumínica y visualmente; la sucesión de espacios en esta dirección, abiertos y cerrados, y la posición de los huecos, permitía atravesarlo desde la entrada del Cuerpo Norte a la Galería Central, y desde ésta al Cuerpo Sur, con el patio incluido en el mismo, hacia los jardines exteriores; sensación reforzada por una sucesión de contraluces hacia la orientación mediodia.

El eje longitudinal se interrumpió y cortó al cegar el ventanal central situado en él. Sobre el hueco al patio se encuentra colocado el cuadro de Goya que representa "La Familia de Carlos IV".

El Cuerpo Norte, centrado en torno a un eje vertical qu€ ordena los espacios principales quedaba, en el proyecto original, abierto al exterior en la planta alta, por un hueco cenital, como el del Panteón romano, sobre una rotonda con columnas. Hay opiniones sobre que, también, podría quedar abierto el centro de la bóveda de
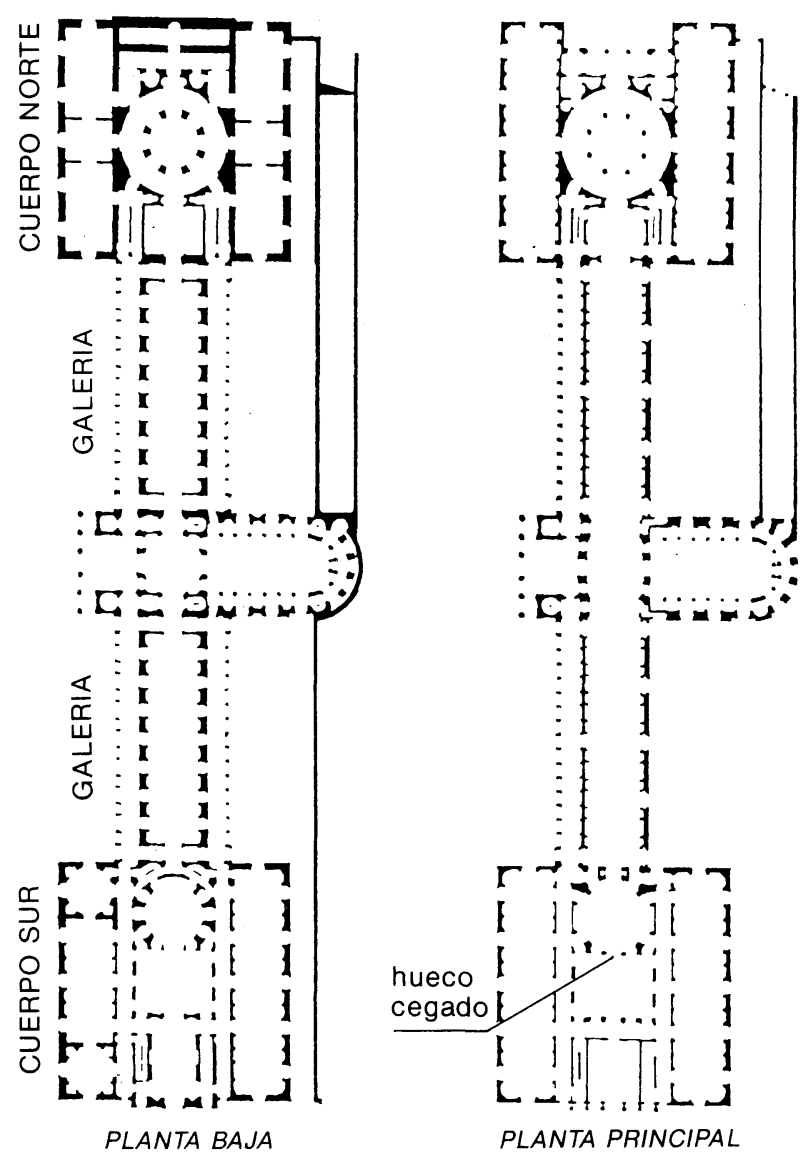

Puede observarse el marcado eje Norte-Sur, sobre él; se señala el hueco de la ventana central que está tapiado.

Museo del Prado, en Madrid. Arquitecto Juan de Villanueva.

la rotonda en la planta inferior, que en su estado inicial quedaba en sótano, semienterrada, debido al nivel de los planos exteriores en esta zona, y que, por tanto, resultaría oscura.

En la actualidad, el óculo superior se encuentra acristalado a dos niveles: en el intradós de la bóveda y al exterior en la cubierta, con lo que se perdió el fuerte contraste de luces y sombras que produciría el soleamiento directo sobre los elementos, resultando una iluminación más atenuada y difusa. En el lugar del posible lucernario sobre el sótano se apoya una escultura del Emperador Carlos I. 


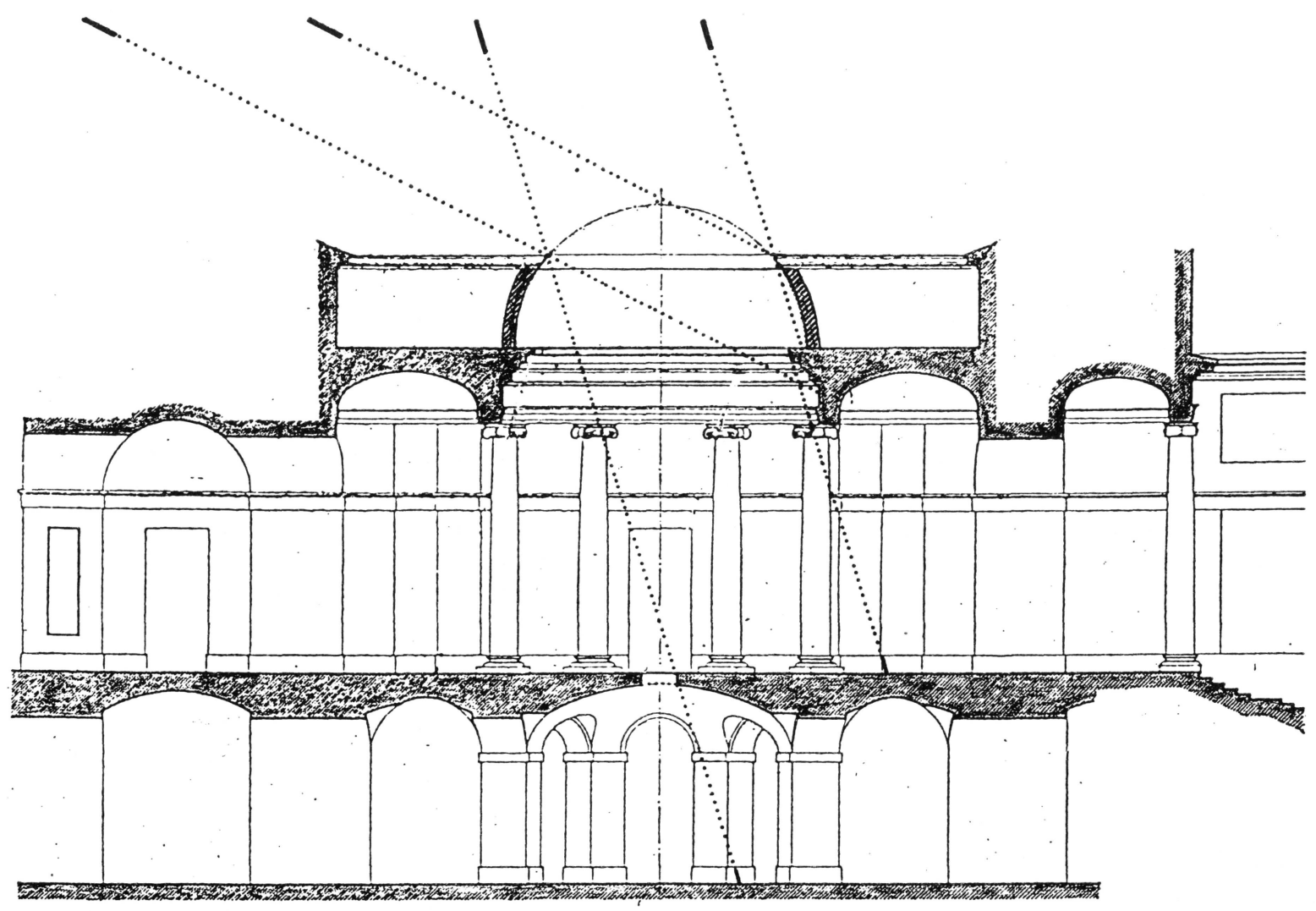

Esquema de la sección del cuerpo norte, según la maqueta que se conserva del proyecto de Juan de Villanueva. Se marca la entrada del sol en invierno y en verano.

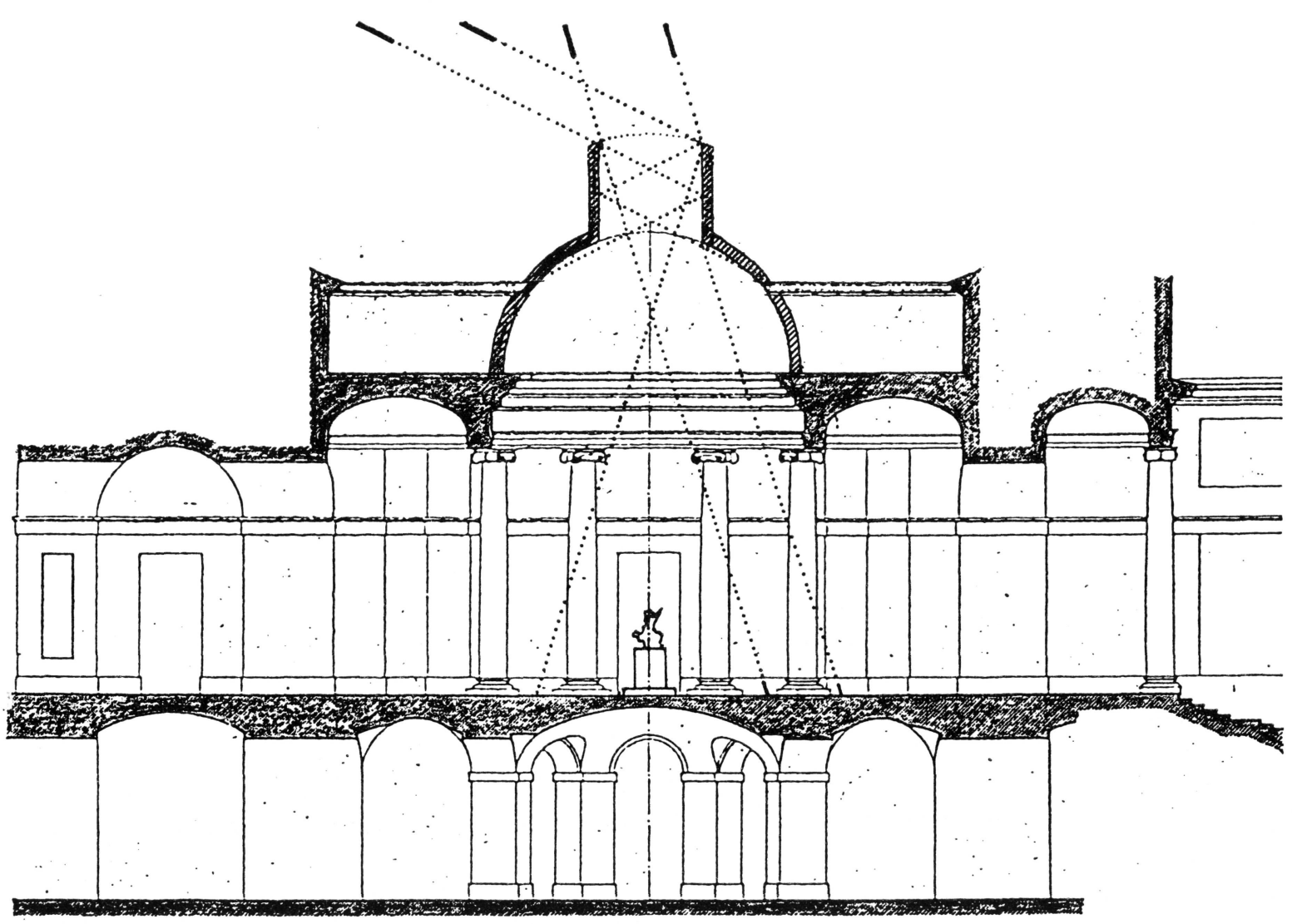

Esquema de la sección del cuerpo norte, en su estado actual. Se marca la entrada del sol en invierno y en verano. 


\section{Monasterio de El Escorial}

En el Monasterio de El Escorial, el acceso al templo se realizaba a través de una alternancia de espacios abiertos y cerrados, claros y oscursos, con todo el juego que esto conlleva de elementos a contraluz como encuadre de imágenes sucesivas, de rebotes de luz que iluminan planos superiores e inferiores, dirigiendo la atención jerarquizadamente a zonas significativas.

Por su situación y orientación, en la iglesia se dan dos momentos límite: por la mañana, los huecos orientados a Saliente de la cúpula son los que frontalmente recogen la luz, lo que desde el interior se aprecia como una fuerte focalización hacia ella; la claridad tiende a subrayar la centralidad del espacio elevándolo en su eje vertical; por la tarde, el gran ventanal sobre el coro dirige un chorro de luz dorada que, atravesando la nave central en toda su longitud, incide sobre el Altar Mayor, permitiendo ver reforzado el carácter lineal del Templo bajo la luz de Poniente.

Disfrutar ahora de este sutil manejo de la luz es casi imposible. La entrada se realiza a través de los mismos espacios abiertos o cerrados, pero los cubiertos per- manecen en un monótono nivel de iluminación artificial durante todo el dia, lo suficientemente alto como para que no haya sucesivas acomodaciones por contrastes marcados en su recorrido, disminuya el tono de los perfiles a contraluz, se pierda la jerarquización de los espacios por la luz, no se aprecie el matiz, la dirección de las sombras se invierta y con ella el sentido de la sucesión de las molduras descomponiendo el orden de los trazados.

Al entrar en la iglesia, la fuerte iluminación eléctrica del altar mayor hace que el resto se pierda como algo difuso.

El ventanal del coro, en muchas ocasiones, se encuentra tapado con una cortina opaca, evitando totalmente la entrada del sol desde esa zona a lo largo del templo; eso hace imposible el distinguir la conformación del fondo ni la decoración del coro; entonces, durante unos minutos, se puede poner en funcionamiento el sistema de iluminación eléctrico, y en vez de la luz tangencial que las pinturas recibían originalmente, incide sobre la decoración, perpendicularmente a la superficie de la bóveda, una potente batería de focos, devastadora de colores, tonos y formas.

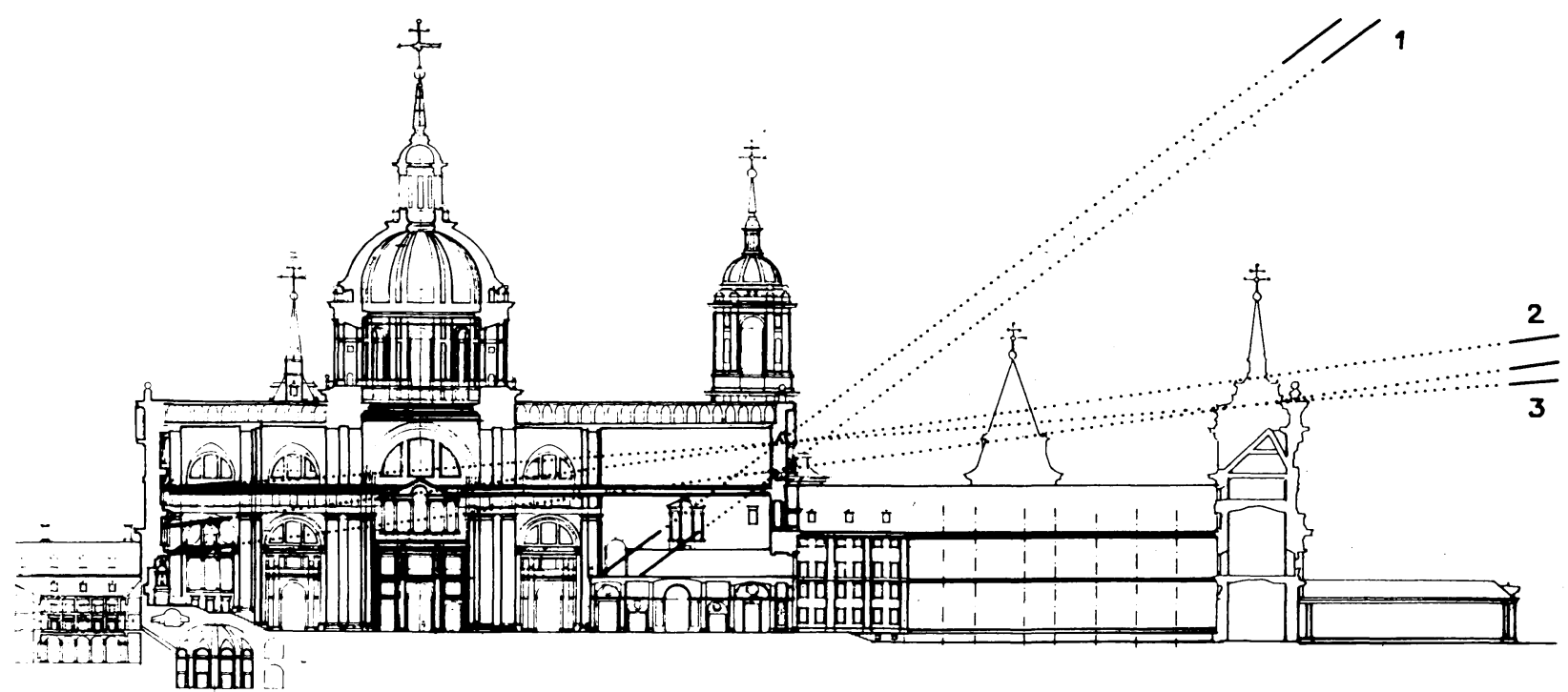

Esquema de la zona iluminada a través del ventanal del coro, orientado a poniente, del Monasterio de El Escorial, sobre una sección por el eje principal del conjunto según Perret. Se marcan las direcciones extremas de los rayos del sol: 1) 21 de junio; 2) 10 de septiembre. 2 de abril; 3) 18 de septiembre - 24 de marzo. 


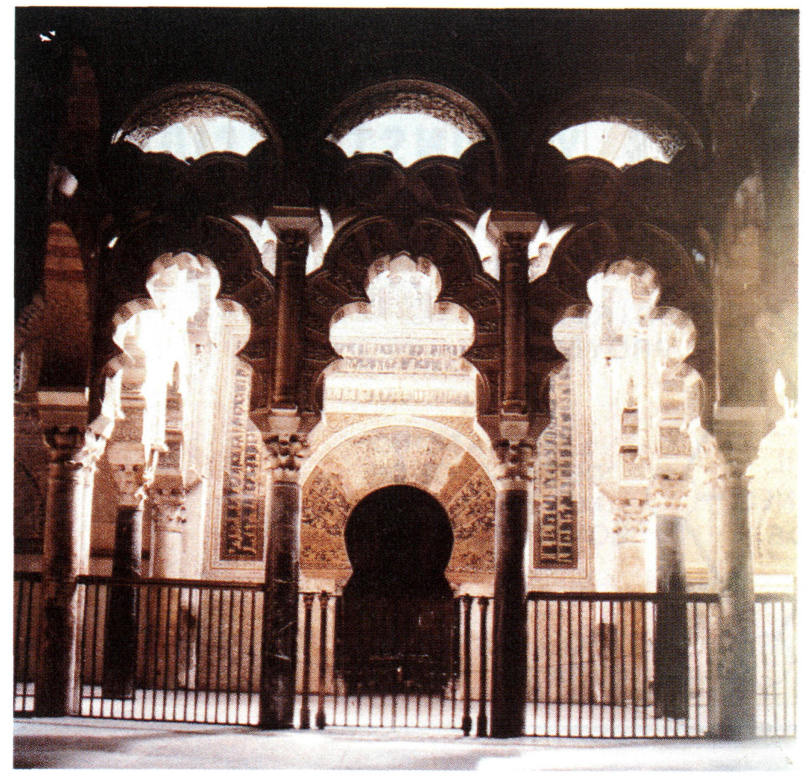

Con iluminación natural

Con iluminación artificial

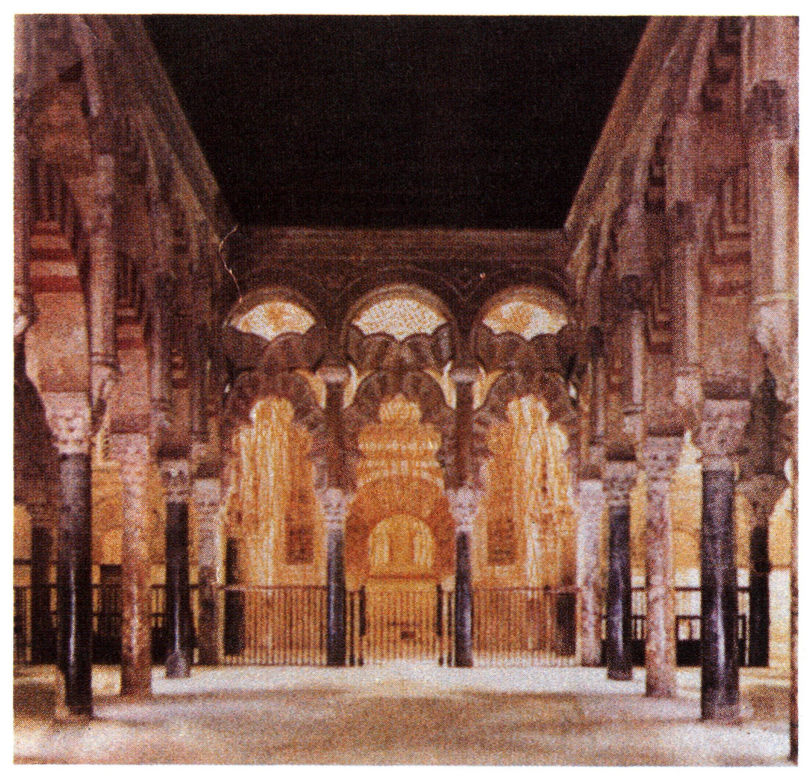

Mihrab y zona adyacente de la Mezquita de Córdoba.

\section{Mezquita de Córdoba}

Respecto a la Mezquita de Córdoba, su percepción original era la de un espacio único, con iluminación natural tenue y amortiguada, ligeramente acentuada y filtrada cenitalmente ante el muro de la quibla, en la que bajo la luz rasante, alta y vertical, el mihrab aparecía como un absorbente agujero oscuro; esta oscuridad acentúa el sentido del hueco, el nicho direccional que marca el eje litúrgico islámico hecho visible, el punto en el que el eje se encuentra con el muro y no debe detener la atención, sino lanzarla en dirección a la Meca como localización final del foco de culto; no es el nicho lo que es sagrado, sino la dirección que indica.

Actualmente, al efectuar una visita a la Mezquita, todo se conjuga para que sea francamente difícil entender este sentido del edificio. Se accede por la ampliación de Almanzor, zona con mayor iluminación natural que el resto (salvo la Catedral incluida en el conjunto), con lo que los términos lejanos se pierden en la oscuridad, y a partir de esa entrada se plantea un camino que va contra todos los obstáculos posibles, de modo que nunca aparezca de forma global. Al final de un serpenteante y puntuante recorrido, saltando de una anécdota a otra, y con unos contrastes lumínicos artificiales tales que la matización espacial original se hace imperceptible, relumbran, brillantemente encendidos los reflectores hacia las bóvedas de la maxura; dia y noche, a todas horas, de modo inmisericorde, los focos aplastan el relieve y la textura de la decoración, alteran el color; la luz orientada hacia lo alto, y en direcciones cruzadas, explota contra las zonas más elevadas uniformándolas.

El mihrab, alterado su sentido litúrgico e invertido en su simbología básica, rabiosamente enfocado emite luz y calor reflejados.

\section{Consideraciones}

Frente a esta deformación del sentido total de las arquitecturas, en su origen, habría que iniciar una etapa en la restauración del patrimonio edificado, la recuperación de la iluminación natural de los edificios, o, por lo menos, la inclusión de sistemas alternativos que no la desvirtuasen.

En muchos casos bastaría con una normativa que ordenase dejar sin encender las iluminaciones eléctricas, al menos durante el día, en edificaciones construidas con anterioridad a su uso generalizado; si para ver algún elemento o detalle se utilizasen temporalmente, que luego se apaguen, dejando el resto del tiempo apreciar los espacios como fueron pensados y realizados, bajo la dinámica y cambiante luz del sol.

Quizá sea ésta una de las propuestas más económicas y simples que pueden hacerse para devolver a las obras su sentido, y a los espectadores la posibilidad de comprensión de la Arquitectura. 